\title{
PENGEMBANGAN MEDIA WAYANG TEMATIK PADA TEMA INDAHNYA NEGERIKU SEBAGAI PENDUKUNG SCIENTIFIC APPROACH KELAS IV SEKOLAH DASAR
}

\author{
Hersa Zafira ${ }^{凶}$, dan Filia Prima Artharina \\ PGSD/Fakultas Ilmu Pendidikan/Universitas PGRI Semarang
}

\section{Info Artikel}

Sejarah Artikel:

Diterima 21 Agt 2017

Disetujui 28 Okt 2017

Dipublikasikan Des 2017

\section{Keywords:}

Development, Thematic

Wayang Media, Beautiful

Theme of my Country,

Scientific Approach

\begin{abstract}
The encouraging background of this research is the learning process that still tends to make students bored. Lessons that do not attract the attention of students, lessons that have not used thematic media, and learning atmosphere that seemed less fun. This type of research is research and development by Borg \& Gall. Subjects in this study were all students of grade IV SD Negeri 08 Tanjungrejo Kudus and SD Negeri 03 Klaling Kudus academic year 2016/2017. Subjects as many as 33 students. Data in this study were obtained through interviews, questionnaires (questionnaire analysis of student needs, questionnaire of teacher needs analysis, student response questionnaire, questionnaire validation of media and material experts and scientific approach questionnaire), observation and documentation. From the assessment by media expert validation and material 1, the percentage of $88.23 \%$ and $87.50 \%$ of the results obtained by the media expert and material 2 obtained $98.5 \%$ percentage and $98.43 \%$ of the results by media experts and material 3 obtained percentage 92,64\% dan 93,75 and the final result of assessment from material expert 4 obtained by percentage $85,93 \%$ while questionnaire of student response get percentage $97,43 \%$ in SD N 08 Tanjungrejo and 98,75\% in SD N 03 Klaling and also scientific questioner Approach is obtained percentage of 90,38\% in SD N 08 Tanjungrejo and equal to 97,00\% in SD N 03 Klaling. The conclusion is the thematic media is worthy of use and can be used as a supporter of the scientific approach on the theme of Beautiful Affairs Negeriku fourth grade elementary school students.
\end{abstract}

\begin{abstract}
Abstrak
Latar belakang yang mendorong penelitian ini adalah proses pembelajaran yang masih cenderung membuat siswa bosan. Pembelajaran yang tidak menarik perhatian siswa, pembelajaran yang belum menggunakan media tematik, dan suasana pembelajaran yang terkesan kurang menyenangkan. Jenis penelitian ini adalah penelitian dan pengembangan oleh Borg \& Gall. Subjek dalam penelitian ini adalah seluruh siswa kelas IV SD Negeri 08 Tanjungrejo Kudus dan SD Negeri 03 Klaling Kudus tahun ajaran 2016/2017. Subjek sebanyak 33 siswa. Data dalam penelitian ini diperoleh melalui wawancara, kuesioner (angket analisis kebutuhan siswa, angket analisis kebutuhan guru, angket respon siswa, angket validasi ahli media dan materi dan angket scientific approach), observasi dan dokumentasi. Dari hasil penilaian oleh validasi ahli media dan materi 1 diperoleh persentase $88,23 \%$ dan $87,50 \%$ hasil penilaian oleh ahli media dan materi 2 diperoleh persentase $98,50 \%$ dan $98,43 \%$ hasil penilain oleh ahli media dan materi 3 diperoleh persentase $92,64 \%$ dan 93,75 dan terakhir hasil penilaian dari ahli materi 4 diperoleh persentase $85,93 \%$ sedangkan angket respon siswa memperoleh persentase 97,43\% di SD N 08 Tanjungrejo dan $98,75 \%$ di SD N 03 Klaling serta angket scientific approach diperoleh persentase sebesar 90,38\% di SD N 08 Tanjungrejo dan sebesar 97,00\% di SD N 03 Klaling. Kesimpulannya adalah media wayang tematik layak digunakan dan dapat dijadikan sebagai pendukung scientific approach pada tema Indahnya Negeriku siswa kelas IV sekolah dasar.
\end{abstract}

(C) 2017 Universitas Muria Kudus
p-ISSN 2087-9385

e-ISSN 2528-696X

Program Studi Pendidikan Guru Sekolah Dasar

Fakultas Keguruan dan Ilmu Pendidikan Universitas Muria Kudus

Kampus UMK Gondangmanis, Bae Kudus Gd. L. 1t I PO. BOX 53

Kudus

Tlp (0291) 438229 ex.147 Fax. (0291) 437198

E-mail:hersazafira@gmail.com 


\section{PENDAHULUAN}

Pendidikan merupakan program pemerintah yang wajib didapatkan oleh semua generasi penerus bangsa. Melalui pendidikan, generasi penerus bangsa memiliki sikap, moral, dan karakter yang baik. Sikap, moral, dan karakter dapat dikembangkan melalui implementasi kurikulum dalam pendidikan. Pelaksanaan Kurikulum 2013 pada tahun 2017 sejalan dengan program pemerintah nawacita, yaitu penguatan pendidikan karakter. Pendidikan karakter mampu merevolusi karakter bangsa melalui kebijakan penataan kembali kurikulum pendidikan nasional dengan mengedepankan aspek seperti pengajaran sejarah pembentukan bangsa, nilai-nilai patriotisme dan cinta Tanah Air, semangat bela negara dan budi pekerti di dalam kurikulum pendidikan Indonesia.

Diberlakukannya Kurikulum 2013 di sekolah dasar banyak memberi pengaruh dalam proses pembelajaran di sekolah dasar. Kurikulum 2013 mencakup 3 kompetensi, yakni kompetensi sikap, kompetensi pengetahuan dan kompetensi keterampilan. Kompetensi tersebut dapat diaktualisasikan dengan pendekatan saintifik (scientific approach). Hal ini ditandaskan Kemendikbud, 2013 dalam (Rusman, 2015: 233) bahwa pendekatan saintifik memiliki beberapa langkah-langkah yakni, mengamati, menanya, menalar, mencoba, dan membentuk jejaring. Penerapan Kurikulum 2013 di sekolah dasar dapat menjadikan siswa lebih kreatif, aktif dan lebih berani membuat simpulan-simpulan dari masalah yang ditemui. Menurut Rusman (2015: 102) "Kurikulum 2013 memiliki 3 ranah penilaian, salah satunya keterampilan siswa dalam tindakan kreatif. Oleh sebab itu, penerapan Kurikulum 2013 dapat menjadikan siswa memiliki jiwa kreatif sejak dini." Tujuan Kurikulum 2013 merujuk pada manusia yang dipersiapkan untuk memiliki kemampuan hidup yang kreatif, aktif, dan inovatif.

Kurikulum 2013 mengandung 18 nilai karakter. Salah satu nilai karakter tersebut yakni cinta tanah air. Hal ini sejalan dengan Kementerian Pendidikan Nasional, dalam (Suyadi, 2013: 8-9). Nilai karakter cinta tanah air dapat diajarkan pada siswa melalui sikap dan perilaku yang mencerminkan rasa bangga dan peduli terhadap budaya bangsa. Misalnya, melestarikan kebudayaan wayang. Wayang tumbuh dan berkembang pada masyarakat Jawa sejak zaman prasejarah. Akan tetapi, pada perkembangannya yang kemudian juga dikenal, dimiliki, dan dikembangkan oleh berbagai etnis dengan berbagai bahasa dan sastra daerah yang lain. Kenyataan bahwa wayang telah melewati berbagai peristiwa sejarah, dari generasi ke generasi, menunjukkan betapa budaya pewayangan telah melekat dan menjadi bagian hidup bangsa Indonesia khususnya Jawa.

Wayang telah diakui UNESCO sebagai Masterpiece of Oral and Intangible Heritage of Humanity ('Karya-karya Agung Lisan dan Tak Benda Warisan Manusia'). Wayang diakui sebagai karya agung yang mempunyai nilai tinggi bagi peradaban umat manusia. Wayang sarat nilai, baik yang tercermin pada karakter tokoh, cerita, maupun berbagai unsur lain yang mendukung. Wayang harus dilestarikan eksistensinya, dan itu menjadi tugas seluruh bangsa di dunia khususnya bangsa Indonesia yang memiliki budaya wayang tersebut (Nurgiyantoro, 2011; Wayang dan Pengembangan Karakter Bangsa diakses pada 4 Mei 2017).

Maka menurut Penulis, wayang dapat digunakan sebagai salah satu alternatif media pembelajaran di sekolah dasar. Media pembelajaran berguna agar pembelajaran lebih menarik dan suasana pembelajaran menjadi lebih menyenangkan. Hal ini sama dengan pendapat Sudjana \& Rivai dalam (Arsyad, 2011: 24) yang menjelaskan bahwa manfaat media pembelajaran dalam proses belajar siswa adalah pembelajaran dapat lebih menarik perhatian siswa. Proses pembelajaran akan lebih mudah dipahami jika seorang guru menggunakan alat atau media untuk mencapai suatu tujuan tersebut. Pembelajaran tanpa menggunakan media akan membuat siswa lebih cepat merasa bosan dan jenuh. Sehingga menimbulkan kurangnya rasa tertarik siswa untuk belajar. Penulis mencoba untuk mengembangkan sebuah media yang nantinya dapat digunakan untuk pembelajaran tematik di sekolah dasar.

Media wayang dapat dibuat menjadi media pembelajaran tematik. Media pembelajaran tematik yang dimaksud adalah dalam satu media sudah mencakup berbagai mata pelajaran yang ada dalam tema, subtema dan pembelajaran. Penulis dalam hal ini akan melakukan observasi mengenai pembelajaran tematik menggunakan sebuah media pada tema Indahnya Negeriku subtema Keindahan Alam Negeriku pembelajaran 5. Pada tema Indahnya Negeriku subtema Keindahan Alam Negeriku pembelajaran 5 terdapat beberapa mata pelajaran, meliputi IPS, IPA, dan Bahasa Indonesia.

Observasi dilakukan di 2 sekolah dasar di Kecamatan Jekulo Kabupaten Kudus, di SD Negeri 08 Tanjungrejo dan SD Negeri 03 Klaling. Saat observasi, Penulis melakukan wawancara dengan guru kelas IV dan mengamati proses pembelajaran di kelas IV sekolah dasar. Hasil wawancara dengan Ibu Fajar Suryani guru 
kelas IV SD Negeri 08 Tanjungrejo dan Ibu Dwi Febriyanti guru kelas IV SD Negeri 03 Klaling ternyata proses pembelajaran masih cenderung membuat siswa bosan, pembelajaran jarang menggunakan media, proses pembelajaran yang masih belum menggunakan media tematik dan suasana pembelajaran yang terkesan kurang menyenangkan. Untuk dapat mengatasi persoalan tersebut, proses penyampaian materi tematik dapat ditunjang dengan menggunakan media pembelajaran.

Menurut Penulis, salah satu contoh media yang dapat digunakan, yakni dengan mengembangkan media wayang tematik. Media wayang merupakan media yang menarik untuk digunakan dalam proses pembelajaran (Oktavianti, 2014; Pengembangan Media GAYANGHETUM dalam Pembelajaran Tematik Terintegrasi Kelas IV SD diakses pada 5 Oktober 2016). Selain untuk media pembelajaran, media wayang juga bisa untuk memperkenalkan dan mengajarkan tentang kebudayaan Indonesia. Dengan perkembangan zaman, wayang banyak digunakan sebagai media yang edukatif dan efektif dalam pembelajaran dengan dikemas berbeda dan menarik minat siswa. Berdasarkan materi Indahnya Negeriku, Penulis mengemas media wayang dengan bentuk baru yaitu Media Wayang Tematik.

Berdasarkan uraian latar belakang, maka rumusan masalah dalam penelitian ini yakni (1) bagaimanakah pengembangan media wayang tematik sebagai pendukung scientific approach? (2) bagaimanakah penerapan media untuk membantu siswa mudah memahami suatu tema dalam pembelajaran tematik?

Adapun yang menjadi tujuan pengembangan ini (1) mengembangkan media wayang tematik sebagai pendukung scientific approach pada tema Indahnya Negeriku kelas IV sekolah dasar. (2) menerapkan media wayang tematik sebagai media pembelajaran pada tema Indahnya Negeriku Kelas IV Sekolah Dasar.

\section{METODOLOGI PENGEMBANGAN}

Penelitian ini menggunakan metode Research and Development $(R \& D)$ yaitu sebuah proses atau langkah-langkah dalam rangka mengembangkan suatu produk baru atau menyempurnakan produk yang sudah ada. "Metode penelitian dan pengembangan adalah metode penelitian yang digunakan untuk menghasilkan produk tertentu, dan menguji keefektifan produk tersebut" (Sugiyono 2007: 407). Penelitian pengembangan bersubjek pada siswa SD kelas IV SD. Jenis penelitian dan pengembangan ini dipilih karena Penulis mengembangkan produk berupa media pembelajaran. Media wayang tersebut sudah ada, namun dikembangkan dalam materi tematik.

Dalam penelitian pengembangan ini, Penulis mengacu pada model penelitian dan pengembangan (R\&D) menurut Borg dan Gall dalam (Sugiyono, 2007: 409) yang terdiri dari beberapa langkah sebagai berikut: (1) melakukan studi pendahuluan, (2) perencanaan, (3) pengembangan draf produk, (4) uji coba perorangan, (5) merevisi hasil uji coba, (6) uji coba terbatas, (7) penyempurnaan produk hasil uji coba terbatas, (8) uji coba pelaksanaan secara luas, (9) penyempurnaan produk akhir dan (10) desiminasi dan implementasi.

Sasaran subjek penelitian penerapan produk pengembangan media wayang tematik ini adalah peserta didik kelas IV SD Negeri 03 Klaling dan SD Negeri 08 Tanjungrejo yang berada di Kecamatan Jekulo Kabupaten Kudus.

\section{HASIL PENGEMBANGAN DAN PEMBAHASAN}

Dalam mengembangkan media wayang tematik Penulis harus melakukan beberapa tahap supaya media dapat berfungsi dengan baik. Media wayang tematik ini merupakan pengembangan dari wayang-wayang yang sudah ada. Mendengar kata wayang, anak-anak sekarang sudah tidak tertarik. Hal ini karena pada era yang sekarang anak lebih suka bermain menggunakan alat elektronik seperti gadget. Media pembelajaran wayang tematik dapat digunakan untuk bermain sekaligus belajar, sehingga dengan siswa bermain wayang juga dapat melestarikan wayang agar tetap terjaga. Wayang tematik juga merupakan proses pengembangan media yang sudah pernah dilakukan oleh Penulis-penulis sebelumnya.

Penulis melakukan tahap pengembangan dengan melakukan tinjauan terhadap materi pembelajaran, membuat desain produk, menyusun sintaks penggunaan media dan kemudian menyusun RPP. Operasional tahapan-tahapan tersebut sebagai berikut.

1. Melakukan tinjauan terhadap materi pembelajaran yang berpedoman pada Kompetensi Inti, Kompetensi Dasar dan Indikator, membaca buku sumber yang berkaitan dengan pembelajaran tematik. Materi tema 6 Indahnya Negeriku subtema 2 Keindahan Alam Negeriku pembelajaran 5.

2. Mengkaji materi sebagai dasar dalam memilih bentuk dan desain media wayang tematik.

3. Menyusun kisi-kisi dan membuat instrumen penilaian untuk menilai kualitas media wayang tematik. 
4. Melakukan validasi instrumen kepada dosen pembimbing.

5. Membuat prototipe media Wayang Tematik. Langkah pertama, Penulis membuat gambar latar/background wayang yang akan dibahas dalam wayang tematik dengan cara menggambar manual dengan tangan. Setelah membuat gambar latar, Penulis mencari gambar tokoh wayang seperti manusia, hewan, tumbuhan dan lain-lain yang akan digunakan dalam media wayang tematik. Langkah selanjutnya, Penulis membuat media wayang tematik dengan menggabungkan antara latar dengan tempat wayang. Dalam membuat media, Penulis membutuhkan bahan kertas karton, mika plastik, gabus busa, kalender ring, lem, gunting.

6. Melakukan validasi media wayang tematik kepada ahli materi dan ahli media untuk mengetahui tingkat kelayakan media dalam pembelajaran.

7. Menyusun sintaks penggunaan media wayang tematik. Sintaks penggunaan media pembelajaran wayang tematik yang dirancang Penulis sebagai berikut.
a. Guru dan peserta didik mempersiapkan media pembelajaran wayang tematik.

b. Guru memberikan penjelasan gambaran tentang proses pembelajaran yang akan dilaksanakan dengan media pembelajaran wayang tematik.

c. Guru mulai menyampaikan materi pembelajaran tematik pada tema 6 Indahnya Negeriku subtema 2 Keindahan Alam Negeriku pembelajaran 5.

d. Peserta didik memperhatikan penjelasan guru mengamati media pembelajaran wayang tematik.

e. Semua peserta didik diminta untuk mencoba menggunakan media wayang tematik.

f. Guru melakukan evaluasi pembelajaran.

8. Menyusun Rencana Pelaksanaan Pembelajaran.

Selanjutnya media wayang tematik melalui tahapan validasi oleh ahli media dan materi. Media tersebut sudah dinyatakan valid. Kemudian media diujicobakan kepada siswa SD 08 Tanjungrejo dan SD 03 Klaling untuk mengetahui manfaat dari media wayang tematik sebagai pendukung scientific approach. Penulis menggunakan instrumen penilaian scientific approach untuk mengetahui keberhasilan media sebagai pendukung pembelajaran saintifik siswa kelas IV sekolah dasar.

Tabel 4.1

Hasil Penilaian Instrumen Scientific Approach Siswa kelas IV SD N 08 Tanjungrejo

\begin{tabular}{|c|c|c|c|c|c|}
\hline $\mathrm{No}$ & Aspek & $\begin{array}{l}\text { Skor } \\
\text { Total }\end{array}$ & $\begin{array}{l}\text { Skor } \\
\text { Ideal }\end{array}$ & $\begin{array}{c}\text { Persen } \\
\text { tase }\end{array}$ & Kriteria \\
\hline 1. & $\begin{array}{c}\text { Aspek } \\
\text { Mengamati }\end{array}$ & 46 & 52 & $\begin{array}{c}88,46 \\
\%\end{array}$ & $\begin{array}{c}\text { Sangat } \\
\text { baik }\end{array}$ \\
\hline 2. & $\begin{array}{c}\text { Aspek } \\
\text { Menanya }\end{array}$ & 51 & 52 & $\begin{array}{c}98,07 \\
\%\end{array}$ & $\begin{array}{c}\text { Sangat } \\
\text { baik }\end{array}$ \\
\hline 3. & $\begin{array}{c}\text { Aspek } \\
\text { Menalar }\end{array}$ & 31 & 39 & $\begin{array}{c}79,48 \\
\%\end{array}$ & $\begin{array}{c}\text { Sangat } \\
\text { baik }\end{array}$ \\
\hline 4. & $\begin{array}{c}\text { Aspek } \\
\text { Mencoba }\end{array}$ & 52 & 52 & $\begin{array}{c}100,00 \\
\%\end{array}$ & $\begin{array}{c}\text { Sangat } \\
\text { baik }\end{array}$ \\
\hline 5 . & $\begin{array}{c}\text { Aspek } \\
\text { Membentuk } \\
\text { Jejaring }\end{array}$ & 55 & 65 & $\begin{array}{c}84,61 \\
\%\end{array}$ & $\begin{array}{c}\text { Sangat } \\
\text { baik }\end{array}$ \\
\hline \multicolumn{5}{|c|}{$\begin{array}{l}\text { Persentase }=\frac{\text { ESkor total }}{\text { SSkor ideal }} \times 100 \% \\
=235 \times 100 \%=\frac{90,38 \%}{260} \%\end{array}$} & $\begin{array}{c}\text { Sangat } \\
\text { baik }\end{array}$ \\
\hline
\end{tabular}

Tabel 4.2

Hasil Penilaian Instrumen Scientific Approach Siswa kelas IV SD N 03 Klaling

\begin{tabular}{|c|c|c|c|c|c|}
\hline No & Aspek & $\begin{array}{l}\text { Skor } \\
\text { Total }\end{array}$ & $\begin{array}{l}\text { Skor } \\
\text { Ideal }\end{array}$ & $\begin{array}{l}\text { Persen } \\
\text { tase }\end{array}$ & Kriteria \\
\hline 1. & $\begin{array}{c}\text { Aspek } \\
\text { Mengamati }\end{array}$ & 78 & 80 & $\begin{array}{c}97,50 \\
\%\end{array}$ & $\begin{array}{c}\text { Sangat } \\
\text { baik }\end{array}$ \\
\hline 2. & $\begin{array}{c}\text { Aspek } \\
\text { Menanya }\end{array}$ & 76 & 80 & $\begin{array}{c}95,00 \\
\%\end{array}$ & $\begin{array}{c}\text { Sangat } \\
\text { baik }\end{array}$ \\
\hline 3. & $\begin{array}{c}\text { Aspek } \\
\text { Menalar }\end{array}$ & 58 & 60 & $\begin{array}{c}97,00 \\
\%\end{array}$ & $\begin{array}{c}\text { Sangat } \\
\text { baik }\end{array}$ \\
\hline 4. & $\begin{array}{c}\text { Aspek } \\
\text { Mencoba }\end{array}$ & 79 & 80 & $\begin{array}{c}98,75 \\
\%\end{array}$ & $\begin{array}{c}\text { Sangat } \\
\text { baik }\end{array}$ \\
\hline 5. & $\begin{array}{c}\text { Aspek } \\
\text { Membentuk } \\
\text { Jejaring }\end{array}$ & 97 & 100 & $\begin{array}{c}97,00 \\
\%\end{array}$ & $\begin{array}{c}\text { Sangat } \\
\text { baik }\end{array}$ \\
\hline \multicolumn{5}{|c|}{$\begin{array}{l}\text { Persentase }=\frac{\sum \text { Skor total }}{\sum \text { Skor ideal }} \times 100 \% \\
=388 \times 100 \%=\frac{97,00 \%}{400}\end{array}$} & $\begin{array}{c}\text { Sangat } \\
\text { baik }\end{array}$ \\
\hline
\end{tabular}

Dilihat dari Tabel 4.1 dan 4.2, hasil penilaian instrumen scientific approach di SD N 08 Tanjungrejo dan SD N 03 Klaling sudah memenuhi kategori sangat baik. 


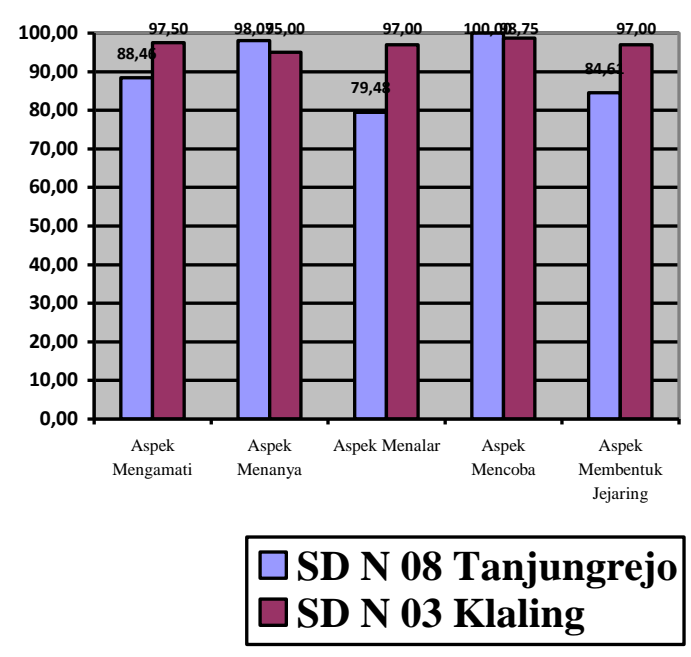

Gambar 4.1 Grafik Diagram Batang Hasil Penilaian Scientific Approach

\section{Validasi ahli media dan materi}

Hasil pengembangan berdasarkan dari perhitungan oleh validasi ahli media dan validasi ahli materi. Dari kisi-kisi angket ahli media meliputi aspek psikologis, aspek organisasi isi, aspek penyajian, aspek keakuratan materi, dan prinsip visual. Selanjutnya kisi-kisi angket ahli materi meliputi aspek kesesuaian, aspek kelayakan, aspek penyajian, aspek kebahasaan, dan aspek kompetensi. Dari hasil analisis penilaian ahli media dan ahli materi 1 tahap pertama (Singgih Adhi Prasetyo S.Sn., M.Pd.) diperoleh hasil sebagai berikut.

Tabel 4.3

Hasil Validasi Ahli Media 1 Tahap Pertama

\begin{tabular}{|c|c|c|c|c|c|}
\hline No & Aspek & $\begin{array}{l}\text { Skor } \\
\text { Total }\end{array}$ & $\begin{array}{l}\text { Skor } \\
\text { Ideal }\end{array}$ & $\begin{array}{c}\text { Persen } \\
\text { tase }\end{array}$ & Kriteria \\
\hline 1. & $\begin{array}{c}\text { Aspek } \\
\text { Psikologis }\end{array}$ & 7 & 8 & $\begin{array}{c}87,50 \\
\%\end{array}$ & $\begin{array}{l}\text { Sangat } \\
\text { layak }\end{array}$ \\
\hline 2. & $\begin{array}{c}\text { Aspek } \\
\text { Organisasi } \\
\text { Isi } \\
\end{array}$ & 19 & 20 & $\begin{array}{c}95,00 \\
\%\end{array}$ & $\begin{array}{l}\text { Sangat } \\
\text { layak }\end{array}$ \\
\hline 3. & $\begin{array}{c}\text { Aspek } \\
\text { Penyajian }\end{array}$ & 11 & 12 & $\begin{array}{c}91,66 \\
\%\end{array}$ & $\begin{array}{l}\text { Sangat } \\
\text { layak }\end{array}$ \\
\hline 4. & $\begin{array}{c}\text { Aspek } \\
\text { Keakuratan } \\
\text { Materi }\end{array}$ & 7 & 8 & $\begin{array}{c}87,50 \\
\%\end{array}$ & $\begin{array}{c}\text { Sangat } \\
\text { layak }\end{array}$ \\
\hline 5. & $\begin{array}{l}\text { Prinsip } \\
\text { Visual }\end{array}$ & 16 & 20 & $\begin{array}{c}80,00 \\
\%\end{array}$ & Layak \\
\hline \multicolumn{5}{|c|}{$\begin{array}{l}\text { Persentase }=\frac{\text { ESkor total }}{\sum \text { Skor ideal }} \times 100 \% \\
=60 \times 100 \%=\frac{88,23}{68} \%\end{array}$} & $\begin{array}{l}\text { Sangat } \\
\text { Layak }\end{array}$ \\
\hline
\end{tabular}

Hasil analisis penilaian ahli media 1 validasi pertama dalam bentuk diagram batang sebagai berikut:

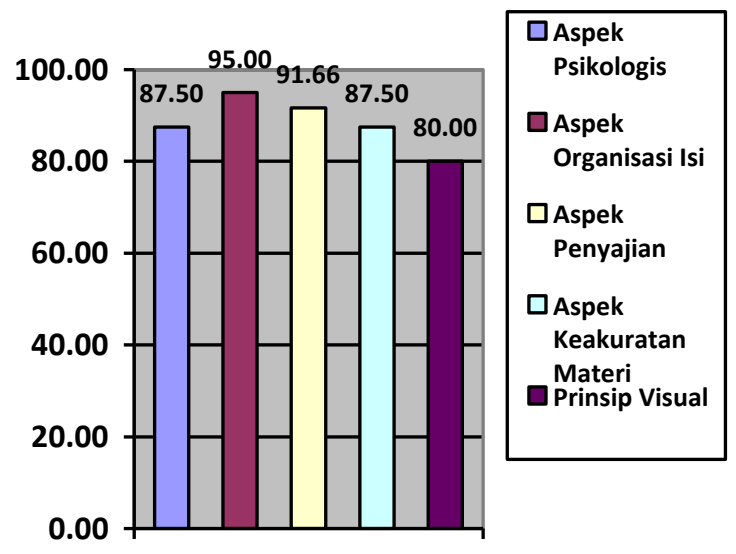

Gambar 4.2 Diagram Batang Hasil Validasi Ahli Media 1 Tahap Pertama

\section{Hasil respon siswa}

Hasil pengembangan media wayang tematik selain berdasarkan dari perhitungan validasi ahli media dan materi, juga berdasarkan respon siswa di kedua sekolah dasar. Setelah media divalidasi dan dinyatakan valid oleh para ahli media dan materi, media tersebut diujicobakan pada 13 siswa SD Negeri 08 Tanjungrejo dan 20 siswa SD Negeri 03 Klaling untuk mengetahui respon dari siswa. Hasil dari respon siswa terhadap media wayang tematik diperoleh persentase sebesar 97,43\% dari siswa SD Negeri 08 Tanjungrejo dan 98,75\% dari siswa SD Negeri 03 Klaling. Dapat dilihat pada tabel sebagai berikut:

Tabel 4.13

Angket Respon Siswa Kelas IV SD Negeri 08

\begin{tabular}{|c|l|l|}
\multicolumn{2}{|c|}{ Tanjungrejo } \\
\hline \multicolumn{2}{|c|}{ Kode } & \multicolumn{2}{c|}{ Skor } \\
\hline 1. & R-1 & 12 \\
\hline 2. & R-2 & 12 \\
\hline 3. & R-3 & 12 \\
\hline 4. & R-4 & 11 \\
\hline 5. & R-5 & 12 \\
\hline 6. & R-6 & 10 \\
\hline 7. & R-7 & 11 \\
\hline 8. & R-8 & 12 \\
\hline 9. & R-9 & 12 \\
\hline 10. & R-10 & \\
\hline 11. & R-11 & \\
\hline 12. & R-12 & \\
\hline 13. & R-13 & \\
\hline
\end{tabular}

Persentase $=\frac{\sum \text { Skor total }}{\sum \text { skor ideal }} \times 100 \%$ 


$$
\begin{aligned}
& =\frac{152}{12 \times 13} \times 100 \% \\
& =\frac{152}{156} \times 100 \% \\
& =0,9743 \times 100 \%=97,43 \%
\end{aligned}
$$

Hasil dari angket respon siswa kelas IV SD Negeri 03 Klaling dapat dilihat pada tabel sebagai berikut:

Tabel 4.14

Angket Respon Siswa Kelas IV SD Negeri 03 Klaling

\begin{tabular}{|c|c|c|c|c|c|}
\hline No. & Kode & Skor & No. & Kode & Skor \\
\hline 1. & R-1 & 12 & 11. & R-11 & 12 \\
\hline 2. & R-2 & 12 & 12. & R-12 & 12 \\
\hline 3. & R-3 & 12 & 13. & R-13 & 12 \\
\hline 4. & R-4 & 12 & 14. & R-14 & 12 \\
\hline 5. & R-5 & 12 & 15. & R-15 & 11 \\
\hline 6. & R-6 & 12 & 16. & R-16 & 12 \\
\hline 7. & R-7 & 12 & 17. & R-17 & 12 \\
\hline 8. & R-8 & 12 & 18. & R-18 & 12 \\
\hline 9. & R-9 & 12 & 19. & R-19 & 12 \\
\hline 10. & R-10 & 10 & 20. & R-20 & 12 \\
\hline
\end{tabular}

Persentase $=\frac{\sum \text { Skor total }}{\sum \text { skor ideal }} \times 100 \%$

$$
\begin{aligned}
& =\frac{237}{12 \times 20} \times 100 \% \\
& =\frac{237}{240} \times 100 \% \\
& =0,9875 \times 100 \%=98,75 \%
\end{aligned}
$$

Penulis memperoleh hasil angket respon siswa kelas IV pada masing masing sekolah dasar, selanjutnya Penulis menyajikan hasil kedua sekolah dasar tersebut dalam tabel berikut:

Tabel 4.15

Hasil Angket Respon Siswa Kelas IV SD N 08 Tanjungrejo dan SD N 03 Klaling

\begin{tabular}{|c|c|}
\hline \multicolumn{2}{|c|}{ Hasil Angket Respon Siswa } \\
\hline SD N 08 & SD N 03 \\
Tanjungrejo & Klaling \\
\hline $97,43 \%$ & $98,75 \%$ \\
\hline
\end{tabular}

Berdasarkan Tabel 4.15 diatas, maka dapat diketahui hasil angket respon siswa dengan menggunakan gambar dalam bentuk diagram batang sebagai berikut:

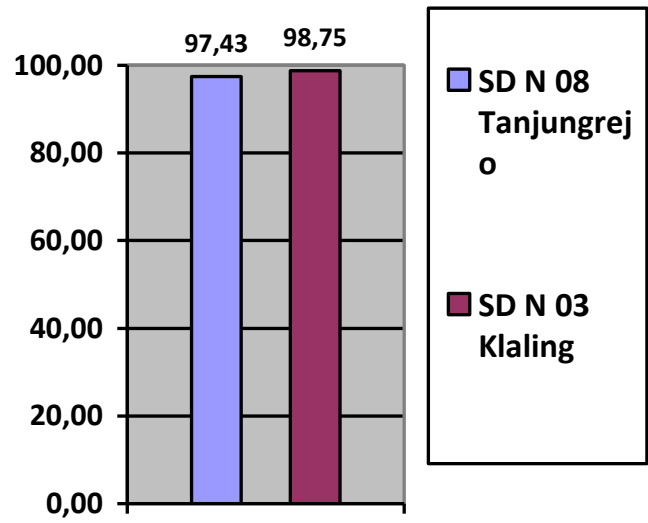

Gambar 4.12 Diagram Batang Hasil Angket Respon Siswa Kedua Sekolah Dasar

\section{SIMPULAN}

Pengembangan media wayang tematik sebagai pendukung scientific approach dinyatakan layak oleh ahli media dan materi 1 dengan perolehan persentase sebesar 88,23\% dan $87,50 \%$, ahli media dan materi 2 sebesar $98,50 \%$ dan $98,43 \%$, ahli media dan materi 3 sebesar 92,64\% dan 93,75\% sedangkan ahli ke 4 hanya menilai materi saja memperoleh persentase sebesar 85,93\%. Media wayang tematik yang dihasilkan oleh Penulis merupakan hasil dari validasi dengan ahli media dan materi. Media wayang tematik adalah media dengan rincian sebagai berikut.

1. Media wayang tematik memiliki 5 gambar latar atau background yang kontekstual

2. Media wayang tematik memiliki beberapa wayang yang kontekstual

3. Wayang terbuat dari kertas evory tebal agar gambar dan warna wayang lebih jelas dan tidak mudah luntur terkena air atau lem.

4. Wadah wayang terbuat dari wadah transparan agar dapat terlihat oleh siswa saat akan digunakan.

5. Area penancapan wayang berupa gabus yang ringan.

6. Media wayang tematik dikemas dalam tas yang mudah dibawa.

Penerapan media wayang tematik untuk membantu siswa mudah memahami tema dalam pembelajaran tematik dapat dilihat pada antusias siswa terhadap media wayang tematik, melalui media wayang tematik, Penulis memperoleh persentase respon siswa sebesar $97,43 \%$ dari siswa SD Negeri 08 Tanjungrejo dan 98,75\% dari siswa SD Negeri 03 Klaling. Antusias siswa 
terhadap media wayang tematik sebagai pendukung scientific approach juga terlihat melalui perolehan persentase sebesar $90,38 \%$ di SD Negeri 08 Tanjungrejo dan $97,00 \%$ di SD Negeri 03 Klaling dengan penilaian per aspek yaitu aspek mengamati, menanya, menalar, mencoba dan membentuk jejaring.

Ketertarikan siswa terhadap media terlihat di setiap aspek seperti pada aspek menanya, siswa aktif bertanya mengenai media dan materi yang disampaikan Penulis melalui media. Pada aspek mencoba, siswa dengan antusias mencoba bercerita dengan media wayang tematik. Sedangkan aspek membentuk jejaring terlihat siswa mampu bekerja kelompok dengan baik, siswa memperhatikan temannya bercerita dan menghargai tanggapan temannya. Menurut hasil tersebut, maka media wayang tematik layak digunakan sebagai pendukung scientific approach dalam pembelajaran tematik tema Indahnya Negeriku subtema Keindahan Alam Negeriku pembelajaran 5 siswa kelas IV Sekolah Dasar.

\section{DAFTAR PUSTAKA}

Arsyad, Azhar. 2011. Media Pembelajaran. Jakarta: Kharisma Putra Utama Offset.

2016. Media Pembelajaran. Jakarta: Kharisma Putra Utama Offset.

Laila, Alfi. 2012. Pengembangan Media “Audio Visual" berupa Video Animasi Sebagai Pendukung Pendekatan Saintifik Materi Piutang Wesel dan Pendiskontoan Piutang Wesel. Jurnal Pendidikan Akuntansi 1 (1), hlm 1-5.

Nurgiyantoro, Burhan. 2011. Wayang dan Pengembangan Karakter Bangsa. Jurnal Pendidikan Karakter 1 (1), hlm 18-34. Diakses pada 4 Mei 2017.

Oktavianti, Rizki. 2014 Pengembangan Media GAYANGHETUM dalam Pembelajaran Tematik Terintegrasi Kelas IV SD N 01 Tegorejo Kabupaten Kendal. Skripsi. Pendidikan Guru Sekolah Dasar. IKIP PGRI Semarang. Semarang: Tidak diterbitkan. Diakses pada 5 Oktober 2016.
Putra, Nusa. 2015. Research \& Development Penelitian dan Pengembangan: Suatu Pengantar. Jakarta: PT Raja Grafindo Persada.

Rusman. 2015. Pembelajaran Tematik Terpadu. Jakarta: PT Raja Grafindo Persada.

Servanda, Niken. 2015. Pengembangan Media Wayang Kupu-kupu pada Pembelajaran Tema Peduli terhadap Lingkungan Siswa Kelas IV Sekolah Dasar. Skripsi. Pendidikan Guru Sekolah Dasar. Universitas PGRI Semarang. Tidak diterbitkan.

Sugiyono. 2007. Metode Penelitian Pendidikan (Pendekatan Kuantitatif, Kualitatif, dan $R \& D)$. Bandung: Alfabeta.

2016. Metode Penelitian Pendidikan (Pendekatan Kuantitatif, Kualitatif, dan $R \& D)$. Bandung: Alfabeta.

Susanto, Ahmad. 2013. Teori Belajar dan Pembelajaran di Sekolah Dasar. Jakarta: PT Prenadamedia Group.

Suyadi. 2013. Strategi Pembelajaran Pendidikan Karakter. Bandung: Remaja Rosdakarya. Diakses pada 13 Juni 2017.

Untari, Mei Fita Asri. 2013. Implementasi Pendekatan Saintifik (Scientific Approach) dalam Pembelajaran di Sekolah Dasar. Prosiding. Diakses pada 5 Oktober 2016.

Wahyudi, Achmat. 2016. Pengembangan Media Wayang Sains Play Book sebagai Penunjang Materi Makhluk Hidup dan Lingkungan kelas IV SD di Kelurahan Pedurungan Kidul Kota Semarang. Skripsi. Pendidikan Guru Sekolah Dasar. Universitas PGRI Semarang.

Yasasusastra, Syahban J. 2011. Mengenal Tokoh Pewayangan. Yogyakarta: Pustaka Mahardika. 